\title{
Fuzzy Soft System and Arrhythmia Classification
}

\author{
Pankaj Srivastava, ${ }^{1}$ Neeraja Sharma, ${ }^{1}$ and C. S. Aparna ${ }^{2}$ \\ ${ }^{1}$ Department of Mathematics, Motilal Nehru National Institute of Technology, Allahabad, Uttar Pradesh 211004, India \\ ${ }^{2}$ Department of Applied Mechanics, Motilal Nehru National Institute of Technology, Allahabad, Uttar Pradesh 211004, India
}

Correspondence should be addressed to Neeraja Sharma; 06.neeraja@gmail.com

Received 11 October 2013; Accepted 12 November 2013; Published 18 February 2014

Academic Editors: S. Deng and S. N. U. A. Kirmani

Copyright (C) 2014 Pankaj Srivastava et al. This is an open access article distributed under the Creative Commons Attribution License, which permits unrestricted use, distribution, and reproduction in any medium, provided the original work is properly cited.

An arrhythmia is an irregularity with the speed or rhythm of the heartbeat. During an arrhythmia, the heart can beat too fast, too slow, or with an irregular rhythm. Most arrhythmias are harmless, but some can be serious or even life threatening. The present paper deals with the classification scheme of arrhythmia commonly occurring in human beings of Southeast Asian countries. Medical knowledge used in practice has been closely studied for modelling user friendly referral system to sharpen arrhythmia diagnosis by experts and this system is tested with satisfactory factor which is measured with degree of match criterion under the domain of considered inputs and computed output.

\section{Introduction}

In Charaka and Sushruta Samhitas there is a description of five types of heart disease, namely, Vatika, Paittika, Kaphaj, Tridoshaj, and Krimij that are caused due to Vata, Pitta, Kapha, triple doshas, and worms, respectively. Hridrog Prakarana deals with the treatment for above-mentioned heart diseases. It appears that many kinds of heart related diseases like arrhythmia have been included under Vatinduced inflammation and respiratory disease on the ground of similarity of symptoms. According to Ayurved, when Pran vayu and Saman vayu along with Avlambak kapha get disturbed due to faulty diet (rich in salt, bitter, and pungent), excessive smoking, and prolonged alcohol consumption, the cardiac rhythm may be slow or fast [1]. Although ancient Chinese pulse theory laid the foundation for the study of arrhythmias and clinical electro physiology in the 5th century $\mathrm{BC}$, the most significant breakthrough in the identification and treatment of cardiac arrhythmias first occurred in the 20th century. Hippocrates stated in his Aphorisms (Section II, number 41): those who are subject to frequent and severe fainting attacks without obvious cause die suddenly. This might be the first description of sudden cardiac death [2]. In 1958, Furman and Robinson showed that the heart could be stimulated by connecting an intracardiac catheter to a stimulator. In the late 1960s, a major breakthrough in our understanding of cardiac arrhythmias came when a reliable recording of the electrogram of the Bundle of His and programmed electrical stimulation of the heart became available for clinical use. The background for these developments came from the work of pioneers such as Hecht, Latour, Puech, and Giraud who, in the 1940s to 1950s, showed that intracardiac catheters could be used to record electrical activity inside the heart and to map cardiac activation [3].

There has been extensive work on techniques of classification of arrhythmia based on databases that may not be relevant for present-day clinical diagnostic systems. This is due to limitation in types of arrhythmia considered in them. The present papaer tries to overcome this limitation. Mahmoodabadi, et al. suggested that Neural Networks cannot respond correctly to unpredictable and abrupt changes encountered in patients because of varying shapes of arrhythmias. In contrast, the application of fuzzy tools is firmly tied to human judgment; therefore the study of human behaviour towards a problem is very important to achieve reasonable results [4].

In the field of medicine, Bellman and Zadeh [5] proposed application of fuzzy tools. In 1973, Zadeh [6] introduced a number of procedures to design and develop fuzzy algorithm for the analysis of complex systems and its decision processes. 
Zong and Jiang [7] presented a fuzzy reasoning approach for ECG beat rhythm detection and classification. They used linguistic variables to represent beat features and fuzzy conditional statements perform reasoning. De Chazal et al. [8] proposed method for the automatic processing of the electrocardiogram for the classification of heartbeats in which allocation of detected heartbeats to one of the five beat classes recommended by ANSI/AAMI (American National Standards Institute/Association for the Advancement of Medical Instrumentation) EC57:1998 standard, that is, normal beat, ventricular ectopic beat (VEB), supraventricular ectopic beat, fusion of a normal and a VEB, or unknown beat type was manually performed on data obtained from the 44 nonpacemaker recordings of the MIT-BIH arrhythmia database. Yeh et al. [9] proposed fuzzy logic method to analyse ECG signals for determining the heartbeat case which can accurately classify and distinguish both normal heartbeats and abnormal heartbeats; Mahmoodabadi et al. [4] selected ECG features which are compared medically accepted normal cases using the fuzzy classifier, and arrhythmias will be detected accordingly. The inference section of a fuzzy classifier implemented expert designed fuzzy rules. Sadiq and Khan [10] presented an automated approach to beat recognition of four different beat types in ECGs, namely, normal beats, ventricular ectopic beats, supraventricular ectopic beats, and fusion beats with the help of feature vector to differentiate between the different beats containing morphological features and beat intervals for each beat. Recently, in soft computing risk assessment scheme for cardiac analysis and hypertension proposed by P. Srivastava and A. Srivastava [11, 12], the system designed on MATLAB Software gives the person the ratio of the risk and may recommend whether person has to live life normally or with diet or with drug treatment, respectively. Srivastava et al. [13] proposed a soft computing classification criterion to design and develop user friendly diagnostic system for Hepatitis B and the clinical data of the patients and the opinions of medical experts have been utilized to design the diagnostic system. Srivastava et al. [15] proposed soft computing diagnostic system for diabetes that sharpens the diagnostic process as well as guides patients to evolve strategies to control their sugar level. Recently, Srivastava and Sharma [16] proposed a soft computing decision making model to handle real life complex problems related with medical sciences.

\section{Materials and Method}

The proposed soft computing system is designed by making use of facts related to Sugeno approach of fuzzy inference. The system is applied to real and fresh data collected from hospitals in and around Allahabad district (U.P., India). The categorization of arrhythmia is done by making use of available data and specific features from ECG appropriate to do the classification are decided upon. The input parameters of the system are framed on the basis of ten factors responsible for arrhythmia and output is the type of arrhythmia classification. The accuracy of the inference is obtained by comparing it with the results provided by expert cardiologists.
The algorithm proposed helps us in designing the following information system. There are three steps as in Algorithm 1.

2.1. Input Parameters. The ten input factors are ventricular rate (VR), PR interval (PRI), QRS duration (QRSd), R-R interval, atrial rate (AR), P-P interval (P-P), P-QRS ratio ( $\mathrm{P}: \mathrm{QRS}), \mathrm{RI}_{2}: \mathrm{RI}_{1}$ ratio, $\mathrm{PI}_{2}: \mathrm{PI}_{1}$ ratio, and $\mathrm{T}$ wave.

(a) Ventricular rate (VR) is categorized in four different fuzzy sets with their membership functions shown in Figure 1 as follows:

(1) slow (S): $<40 \mathrm{bpm}$,

(2) normal (N): 40 to $100 \mathrm{bpm}$,

(3) high (H): 100 to $150 \mathrm{bpm}$,

(4) very high ( $\mathrm{VH})$ : >150 bpm,

(1) $\mu_{\text {Slow }}(x)= \begin{cases}1 & x \leq 55 \\ \frac{(60-x)}{5} & 55<x<60 \\ 0 & x \geq 60\end{cases}$

(2) $\mu_{\text {Normal }}(x)= \begin{cases}0, & x \leq 55 \text { or } x \geq 105 \\ \frac{(x-55)}{5} & 55<x<60 \\ 1, & 60 \leq x \leq 100 \\ \frac{(105-x)}{5} & 100<x<105\end{cases}$

(3) $\mu_{\text {High }}(x)= \begin{cases}0, & x \leq 100 \text { or } x \geq 160 \\ \frac{(x-100)}{5} & 100<x<105 \\ 1, & 105 \leq x \leq 155 \\ \frac{(160-x)}{5} & 155<x<160\end{cases}$

(4) $\mu_{\text {Very High }}(x)= \begin{cases}0, & x \leq 155 \\ \frac{(x-155)}{5} & 155<x<160 \\ 1, & x \geq 160 .\end{cases}$

(b) PR interval (PRI) which represents atrial depolarization is categorized in three different fuzzy sets shown in Figure 2 with their membership functions as follows:

(1) narrow $(\mathrm{Na}):<120 \mathrm{~ms}$,

(2) normal (N): 120-200 ms, 
STEP 1: Algorithm for Fuzzification Mechanism

(1) Input-Fuzzy System with suitable " $n$ " parameters

$A_{i}, i=1,2, \ldots, n$

(2) $i \leftarrow 1$

While $i \leq n$ do

(1) Categorize in $n_{i}$ fuzzy sets $X_{j}$ in linguistic variables, $j=1,2, \ldots, n_{i}$

while $j \leq n_{i}$ do

(1) Design suitable membership function $\mu_{X_{j}}$ end while

\section{end while}

STEP 2: Algorithm for Fuzzy Rule Base and Defuzzification Mechanism

(1) Input- " $n_{i}$ " linguistic variables $X_{j}, i=1,2, \ldots, n$ and $j=1,2, \ldots, n_{i}$

(2) Input- " $m$ " output parameter $Y_{k}, k=1,2, \ldots, m$

(3) Develop " $r$ " If-Then Fuzzy Rules $R_{p}$ in consultation with medical experts, $p=1,2, \ldots, r$

(4) Input-Fuzzy Rule Base $R_{p}$

(5) Input-Values of parameters $A_{i}$

(6) $p \leftarrow 1$

while $p \leq r$ do

(1) Calculate firing strength $w_{p}=\operatorname{AND} A_{i}, i=1,2, \ldots, n$

(2) $Z_{p}=p$ th rule's consequent fuzzy set.

end while

(7) Final Output of the fuzzy system $Z=\sum_{p=1}^{r} \frac{z_{p} w_{p}}{w_{p}}$

(8) Evaluated Diagnosis (ED) = Final output

\section{STEP 3: Algorithm for Satisfactory Factor Mechanism}

(1) Input-Evaluated Diagnosis (ED), Observed Diagnosis (OD)

(2) Input- " $n$ " input parameter $A_{i}, i=1,2, \ldots, n$ and output result $Z$

(3) $i \leftarrow 1$

(4) $\mathrm{DM}_{T}=1$

while $i \leq n$ do

(1) Calculate $\operatorname{DM}\left(A_{i}\right)=2 \mu_{A_{j}}-1$

(2) $\mathrm{DM}_{T}=\mathrm{DM}_{T} \operatorname{AND} \operatorname{DM}\left(A_{i}\right)$

end while

(5) Calculate $\mathrm{DM}_{O}=\mathrm{DM}(Z)=2 \mu_{Z}-1$

(6) Evaluate Satisfactory Factor $(S F)=\left|D_{T}-D_{O}\right|$

Algorithm 1

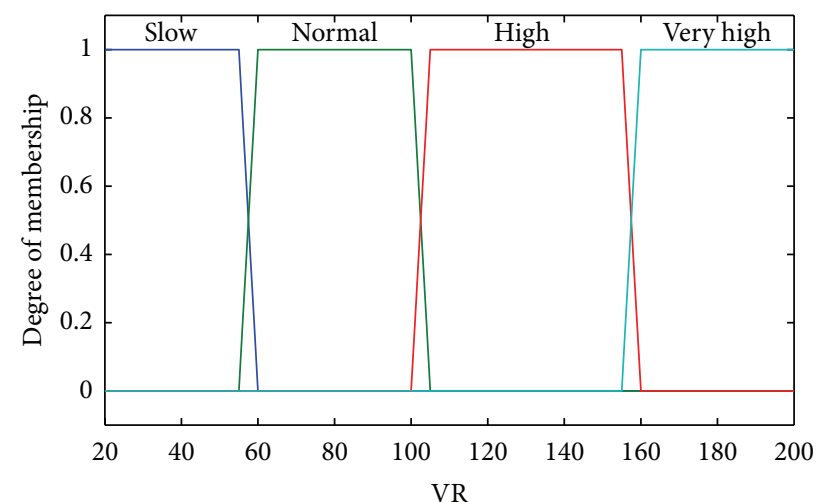

FIGURE 1: Ventricular rate.

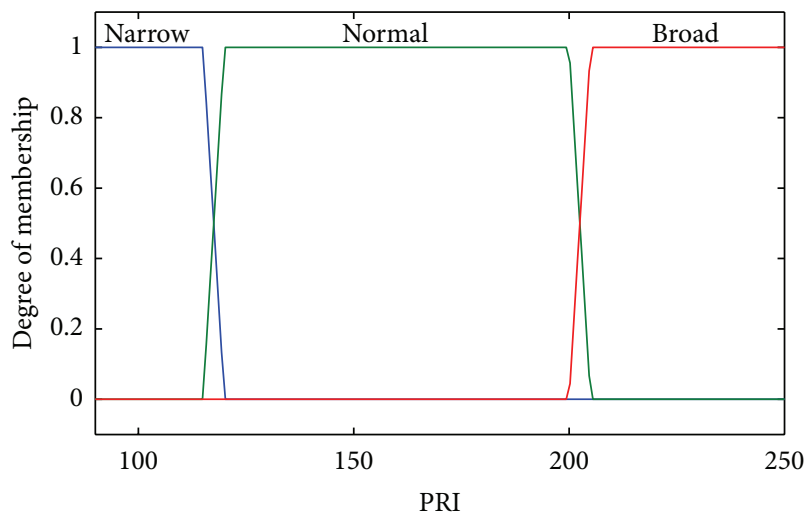

FIGURE 2: PR interval. 
(3) broad (B): >200 ms,

(1) $\mu_{\text {Narrow }}(x)= \begin{cases}1 & x \leq 115 \\ \frac{(120-x)}{5} & 115<x<120 \\ 0 & x \geq 120\end{cases}$

(2) $\mu_{\text {Normal }}(x)= \begin{cases}0 & x \leq 115 \text { or } x \geq 205 \\ \frac{(x-115)}{5} & 115<x<120 \\ 1, & 120 \leq x \leq 200 \\ \frac{(205-x)}{5} & 200<x<205\end{cases}$

(3) $\mu_{\text {Broad }}(x)= \begin{cases}0, & x \leq 200 \\ \frac{(x-200)}{5} & 200<x<205 \\ 1, & x \geq 205 .\end{cases}$

(c) QRS duration (QRSd) is categorized in three different fuzzy sets having their membership functions shown in Figure 3 as follows:

(1) narrow $(\mathrm{Na}):<60 \mathrm{~ms}$,

(2) normal (N): 60-100 ms,

(3) $\operatorname{broad}(\mathrm{B})$ : $>100 \mathrm{~ms}$,

(1) $\mu_{\text {Narrow }}(x)= \begin{cases}1 & x \leq 55 \\ \frac{(60-x)}{5} & 55<x<60 \\ 0 & x \geq 60\end{cases}$

(2) $\mu_{\text {Normal }}(x)= \begin{cases}0 & x \leq 55 \text { or } x \geq 105 \\ \frac{(x-55)}{5} & 55<x<60 \\ 1, & 60 \leq x \leq 100 \\ \frac{(105-x)}{5} & 100<x<105\end{cases}$

(3) $\mu_{\text {Broad }}(x)= \begin{cases}0, & x \leq 100 \\ \frac{(x-100)}{5} & 100<x<105 \\ 1, & x \geq 105 .\end{cases}$

(d) R-R interval (RR) is categorized in three different fuzzy sets with their membership functions shown in Figure 4 as follows:

(1) short (S) $<0.60: \mathrm{sec}$,

(2) normal (N): 0.6-1 sec,

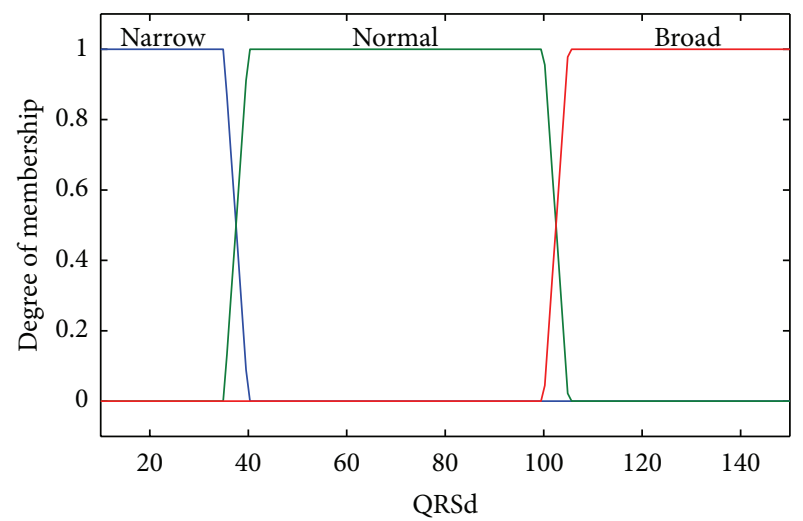

FIGURE 3: QRS duration.

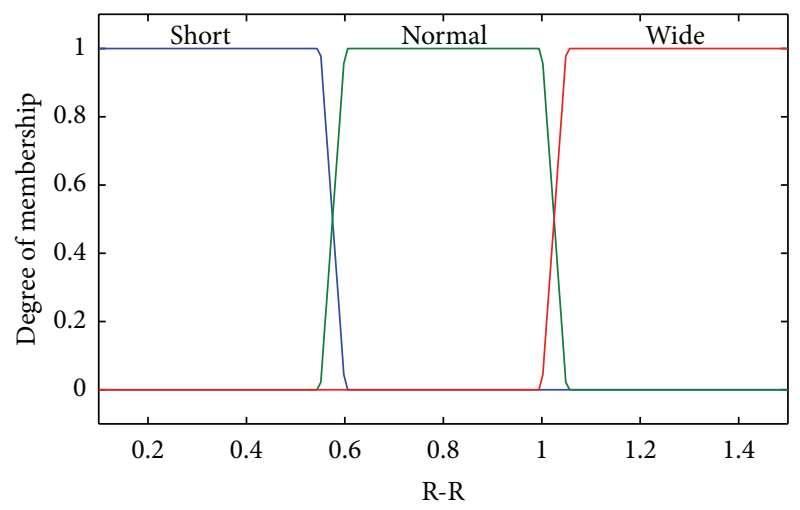

Figure 4: R-R interval.

(3) wide (W): $>1 \mathrm{sec}$,

(1) $\mu_{\text {Short }}(x)= \begin{cases}1 & x \leq 0.55 \\ \frac{(0.6-x)}{0.05} & 0.55<x<0.6 \\ 0 & x \geq 0.6\end{cases}$

(2) $\mu_{\text {Normal }}(x)= \begin{cases}0 & x \leq 0.55 \text { or } x \geq 1.05 \\ \frac{(x-0.55)}{0.05} & 0.55<x<0.6 \\ 1, & 0.6 \leq x \leq 1.00 \\ \frac{(1.05-x)}{0.05} & 1.00<x<1.05\end{cases}$

(3) $\mu_{\text {Wide }}(x)= \begin{cases}0, & x \leq 1.00 \\ \frac{(x-1.00)}{0.05} & 1.00<x<1.05 \\ 1, & x \geq 1.05\end{cases}$

(e) Atrial rate (AR) which is the Atrial rhythm calculated by $\mathrm{P}$ waves is categorized in six different fuzzy sets shown in Figure 5 as follows:

(1) slow (S): <60 bpm,

(2) normal (N): 60-100 bpm,

(3) little bit high (LH): 100-150 bpm, 


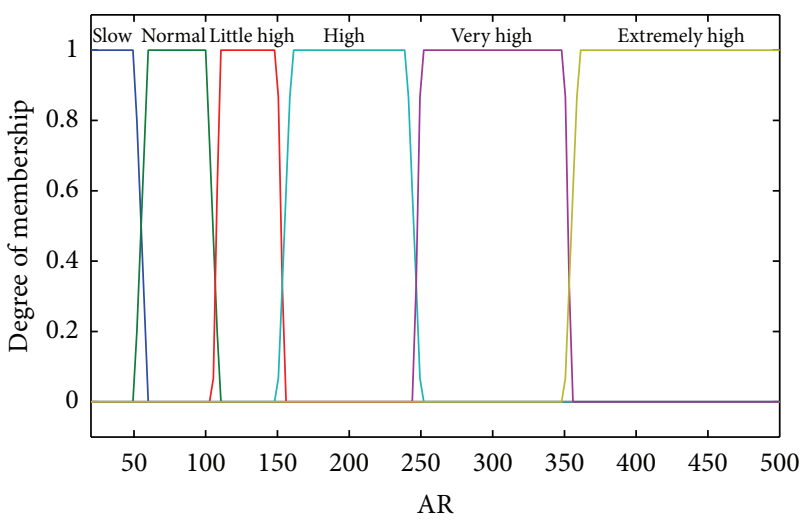

Figure 5: Atrial rate.

(4) high (H): 150-250 bpm,

(5) very high (VH): $250-350 \mathrm{bpm}$,

(6) extremely high (EH): > $350 \mathrm{bpm}$,

(1) $\mu_{\mathrm{S}}(x)= \begin{cases}1 & x \leq 50 \\ \frac{(60-x)}{10} & 50<x<60 \\ 0 & x \geq 60\end{cases}$

(2) $\mu_{\mathrm{N}}(x)= \begin{cases}0 & x \leq 50 \text { or } x \geq 110 \\ \frac{(x-50)}{10} & 50<x<60 \\ 1, & 60 \leq x \leq 100 \\ \frac{(110-x)}{10} & 100<x<110\end{cases}$

(3) $\mu_{\mathrm{LH}}(x)= \begin{cases}0 & x \leq 105 \text { or } x \geq \\ \frac{(x-105)}{5} & 105<x<110 \\ 1, & 110 \leq x \leq 150 \\ \frac{(155-x)}{5} & 150<x<155\end{cases}$

(4) $\mu_{\mathrm{H}}(x)= \begin{cases}0 & x \leq 150 \text { or } x \geq 250 \\ \frac{(x-150)}{10} & 150<x<160 \\ 1, & 160 \leq x \leq 240 \\ \frac{(250-x)}{10} & 240<x<250\end{cases}$

(5) $\mu_{\mathrm{VH}}(x)= \begin{cases}0 & x \leq 245 \text { or } x \geq 355 \\ \frac{(x-245)}{5} & 245<x<250 \\ 1, & 250 \leq x \leq 350 \\ \frac{(355-x)}{5} & 350<x<355\end{cases}$

(6) $\mu_{\mathrm{EH}}(x)= \begin{cases}0, & x \leq 350 \\ \frac{(x-350)}{5} & 350<x<360 \\ 1, & x \geq 360 .\end{cases}$ (f) P-P interval (PP) is categorized in three different fuzzy sets with their membership functions shown in Figure 6 as follows:

(1) short (S): $<0.60 \mathrm{sec}$,

(2) normal (N): 0.6-1 sec,

(3) wide $(\mathrm{W}):>1 \mathrm{sec}$

(1) $\mu_{\text {Short }}(x)= \begin{cases}1 & x \leq 0.55 \\ \frac{(0.6-x)}{0.05} & 0.55<x<0.6 \\ 0 & x \geq 0.6\end{cases}$

(2) $\mu_{\text {Normal }}(x)= \begin{cases}0 & x \leq 0.55 \text { or } x \geq 1.05 \\ \frac{(x-0.55)}{0.05} & 0.55<x<0.6 \\ 1, & 0.6 \leq x \leq 1.00 \\ \frac{(1.05-x)}{0.05} & 1.00<x<1.05\end{cases}$

(3) $\mu_{\text {Wide }}(x)= \begin{cases}0, & x \leq 1.00 \\ \frac{(x-1.00)}{0.05} & 1.00<x<1.05 \\ 1, & x \geq 1.05 .\end{cases}$

(g) $\mathrm{P}$-QRS ratio (P:QRS) shows the ratio of $\mathrm{P}$ wave to QRS wave in one cardiac cycle. It is categorized in the following three different fuzzy sets with their membership functions shown in Figure 7:

(1) low (L): $<1$,

(2) desirable (D): $=1$,

(3) high $(\mathrm{H}):>1$,

$$
\begin{aligned}
& \text { (1) } \mu_{\text {Low }}(x)= \begin{cases}1 & x \leq-2 \\
1-2\left(\frac{x+2}{6}\right)^{2} & -2<x \leq 1 \\
2\left(\frac{x-4}{6}\right)^{2} & 1<x \leq 4 \\
0, & 4<x\end{cases} \\
& \text { (2) } \mu_{\text {High }}(x)= \begin{cases}0 & x \leq-2 \\
2\left(\frac{x+2}{6}\right)^{2} & -2<x \leq 1 \\
1-2\left(\frac{x-4}{6}\right)^{2} & 1<x \leq 4 \\
1, & 4<x .\end{cases}
\end{aligned}
$$

(h) $\mathrm{RI}_{2}: \mathrm{RI}_{1}$ ratio is the ratio of two successive $\mathrm{R}-\mathrm{R}$ intervals. It is categorized in the following three fuzzy factors with their membership functions shown in Figure 8:

(1) low (L): $<1$,

(2) desirable (D): = 1, 


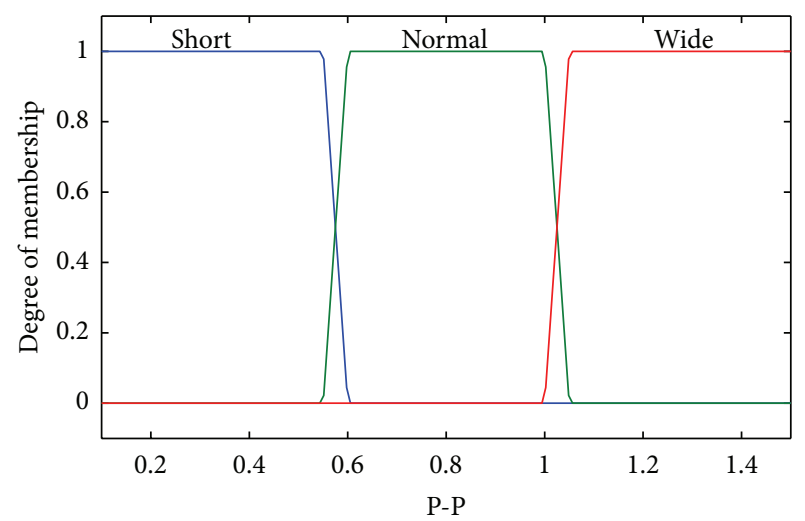

Figure 6: P-P interval.

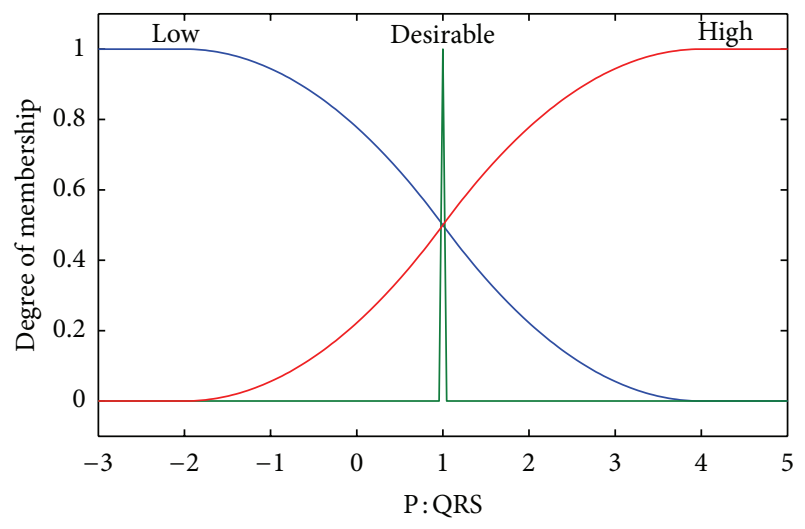

FIGURE 7: P : QRS ratio.

(3) high (H): >1,

$$
\begin{aligned}
& \text { (1) } \mu_{\text {Low }}(x)= \begin{cases}1 & x \leq-2 \\
1-2\left(\frac{x+2}{6}\right)^{2} & -2<x \leq 1 \\
2\left(\frac{x-4}{6}\right)^{2} & 1<x \leq 4 \\
0, & 4<x\end{cases} \\
& \text { (2) } \mu_{\text {High }}(x)= \begin{cases}0 & x \leq-2 \\
2\left(\frac{x+2}{6}\right)^{2} & -2<x \leq 1 \\
1-2\left(\frac{x-4}{6}\right)^{2} & 1<x \leq 4 \\
1, & 4<x .\end{cases}
\end{aligned}
$$

(i) $\mathrm{PI}_{2}: \mathrm{PI}_{1}$ ratio is the ratio of two successive P-P intervals. It is categorized in following three fuzzy factors with their membership functions shown in Figure 9:

(1) low (L): <1,

(2) desirable (D): =1,

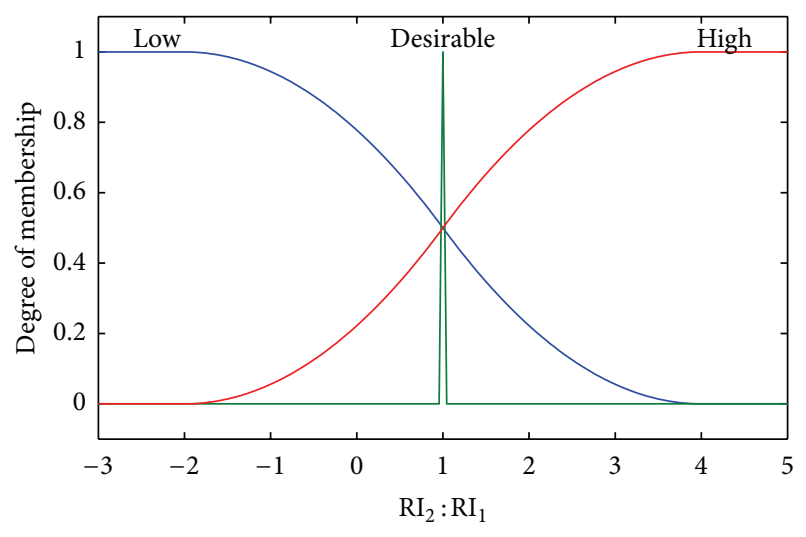

FIGURE 8: $\mathrm{RI}_{2}: \mathrm{RI}_{1}$ ratio.

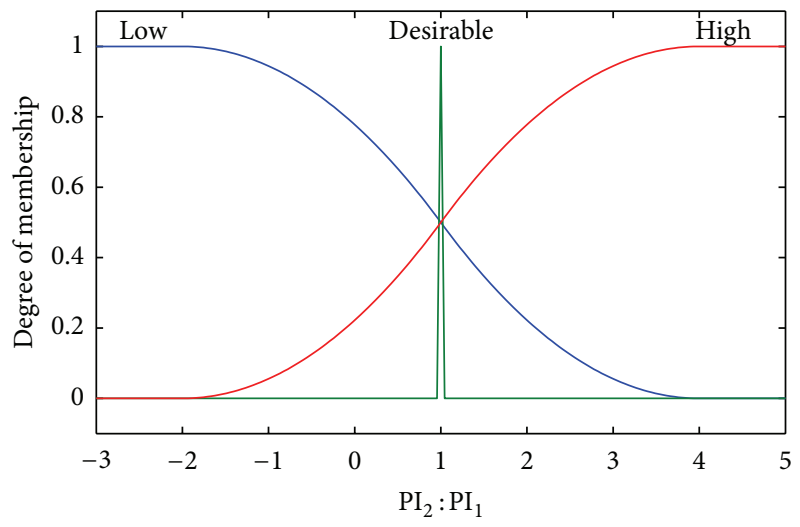

FIGURE 9: $\mathrm{PI}_{2}: \mathrm{PI}_{1}$ ratio.

(3) $\operatorname{high}(\mathrm{H}): i^{1}$,

$$
\begin{aligned}
& \text { (1) } \mu_{\text {Low }}(x)= \begin{cases}1 & x \leq-2 \\
1-2\left(\frac{x+2}{6}\right)^{2} & -2<x \leq 1 \\
2\left(\frac{x-4}{6}\right)^{2} & 1<x \leq 4 \\
0, & 4<x\end{cases} \\
& \text { (2) } \mu_{\text {High }}(x)= \begin{cases}0 & x \leq-2 \\
2\left(\frac{x+2}{6}\right)^{2} & -2<x \leq 1 \\
1-2\left(\frac{x-4}{6}\right)^{2} & 1<x \leq 4 \\
1, & 4<x .\end{cases}
\end{aligned}
$$

(j) $\mathrm{T}$ wave is categorized in three fuzzy sets shown in Figure 10 with their membership functions as follows:

(1) negative $(\mathrm{N}):<0$,

(2) isolated (I): $=0$, 


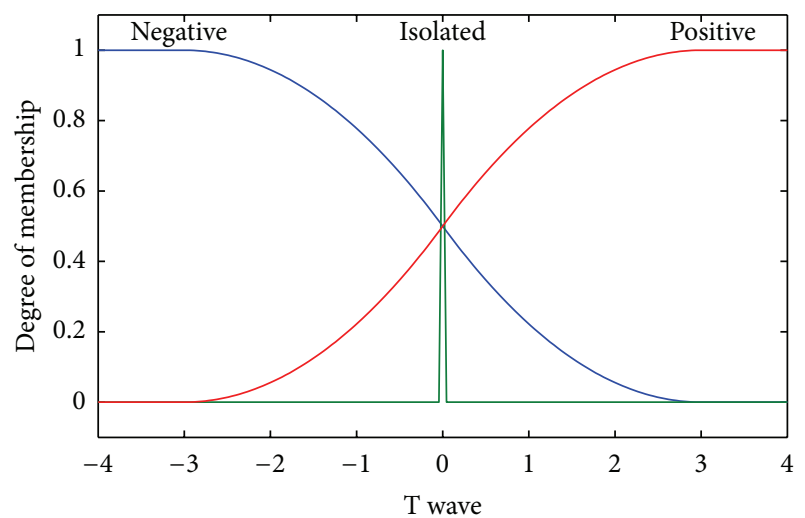

Figure 10: T wave.

(3) positive $(\mathrm{P})$ : $>0$,

$$
\begin{aligned}
& \text { (1) } \mu_{\text {Negative }}(x)= \begin{cases}1 & x \leq-3 \\
1-2\left(\frac{x+3}{6}\right)^{2} & -3<x \leq 0 \\
2\left(\frac{x-3}{6}\right)^{2} & 0<x \leq 3 \\
0, & 3<x\end{cases} \\
& \text { (2) } \mu_{\text {Positive }}(x)= \begin{cases}0 & x \leq-3 \\
2\left(\frac{x+3}{6}\right)^{2} & -3<x \leq 0 \\
1-2\left(\frac{x-3}{6}\right)^{2} & 0<x \leq 3 \\
1, & 3<x .\end{cases}
\end{aligned}
$$

2.2. Output Parameter. The abnormalities in rhythm of the heart contribute to a number of arrhythmia of which we have taken thirteen types as outputs for the classification of arrhythmia. These are as follows: Normal (N), Sinus Tachycardia (ST), Atrial Tachycardia (AT), Atrial Flutter (AF), Atrial Fibrillation (AFb), Ventricular Tachycardia (VT), Sinus Bradycardia (SB), First AV Block (1st B), Second AV Block Type 1 (2nd B1), Second AV Block Type 2 (2nd B2), Third AV Block (3rd B), Premature Atrial Contraction (PAC), and Premature Ventricular Contraction (PAC). Spikes are used to represent these outputs as given in Figure 11.

2.3. Fuzzy Inference System. Evaluation of ECG signals for arrhythmia detection consists of the determination of several characteristics of the signal. In order to classify different types of arrhythmia fifty five rules are constructed with the help of medical experts. They are given in Table 1 .

The output $Z_{i}$, that is, conclusion part of a rule is weighted by the firing strength $w_{i}$ of the rule which is calculated by using AND operation on each antecedent $A_{j}$, where $j$ is the number of inputs used in each rule $i$ as follows:

$$
w_{i}=\operatorname{AND}\left\{A_{j}\right\}, \quad i=1, \ldots, 16 .
$$

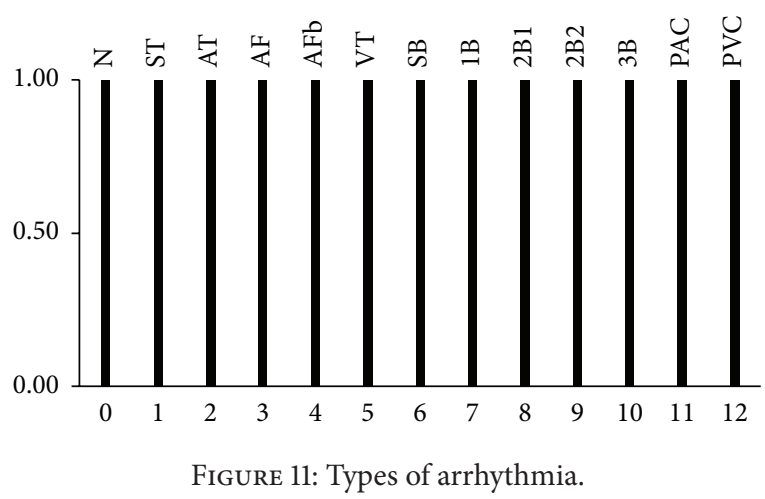

This firing strength is further used in finding the final conclusion of the proposed system using the defuzzification of weighted average of all rule outputs $Z_{i}, i=1, \ldots, 16$.

The final output of the system is calculated by $\sum_{i=0}^{16}\left(Z_{i} w_{i} / w_{i}\right)$.

In order to know to what extent our result is satisfied by given inputs and observed outputs, we make use of Degree of Match algorithm to compute satisfactory factor [17].

Ten cases are discussed below to show the effectiveness of the proposed system.

\subsection{Case Study}

Case 1. The ECG record of the concerned patient is manually calculated as follows.

$\mathrm{VR}=110 \mathrm{bpm}, \mathrm{PRI}=90 \mathrm{~ms}, \mathrm{QRSd}=100 \mathrm{~ms}, \mathrm{AR}=$ $410 \mathrm{bpm}, \mathrm{R}-\mathrm{R}$ interval $=0.46 \mathrm{sec}, \mathrm{P}-\mathrm{P}$ interval $=0.15 \mathrm{sec}$, $\mathrm{P}: \mathrm{QRS}=2, \mathrm{RI}_{2}: \mathrm{RI}_{1}=0.7, \mathrm{PI}_{2}: \mathrm{PI}_{1}=0.9$ and $\mathrm{T}$ wave is positive.

The membership functions designed for input parameters are used to fuzzify the crisp inputs which are transformed into fuzzy outputs by making use of the constructed fuzzy IF-THEN rules and finally defuzzified by using the weighted average function defined above.

The defuzzification is shown in Figure 12 which shows the output that is, Arrhythmia = 4, which stands for the Atrial Fibrillation $(\mathrm{AFb})$. This diagnosis matches the observed diagnosis by medical experts.

In order to measure satisfactory factor, values of Degree of Match of input parameters are computed and total Degree of Match of inputs $\mathrm{DM}_{T}$ is given below:

$$
\begin{aligned}
\mathrm{DM}_{T} & =\min \{1,1,1,1,1,1,0.778,0.595,0.533,0.778\} \\
& =0.533 .
\end{aligned}
$$

Degree of Match of output $\mathrm{DM}_{O}$ is 1; hence our satisfactory factor is $D=\left|\mathrm{DM}_{T}-\mathrm{DM}_{\mathrm{O}}\right|=|0.533-1|=0.467$ which lies between 0 and 1 and near to zero, that meets level of satisfaction. 


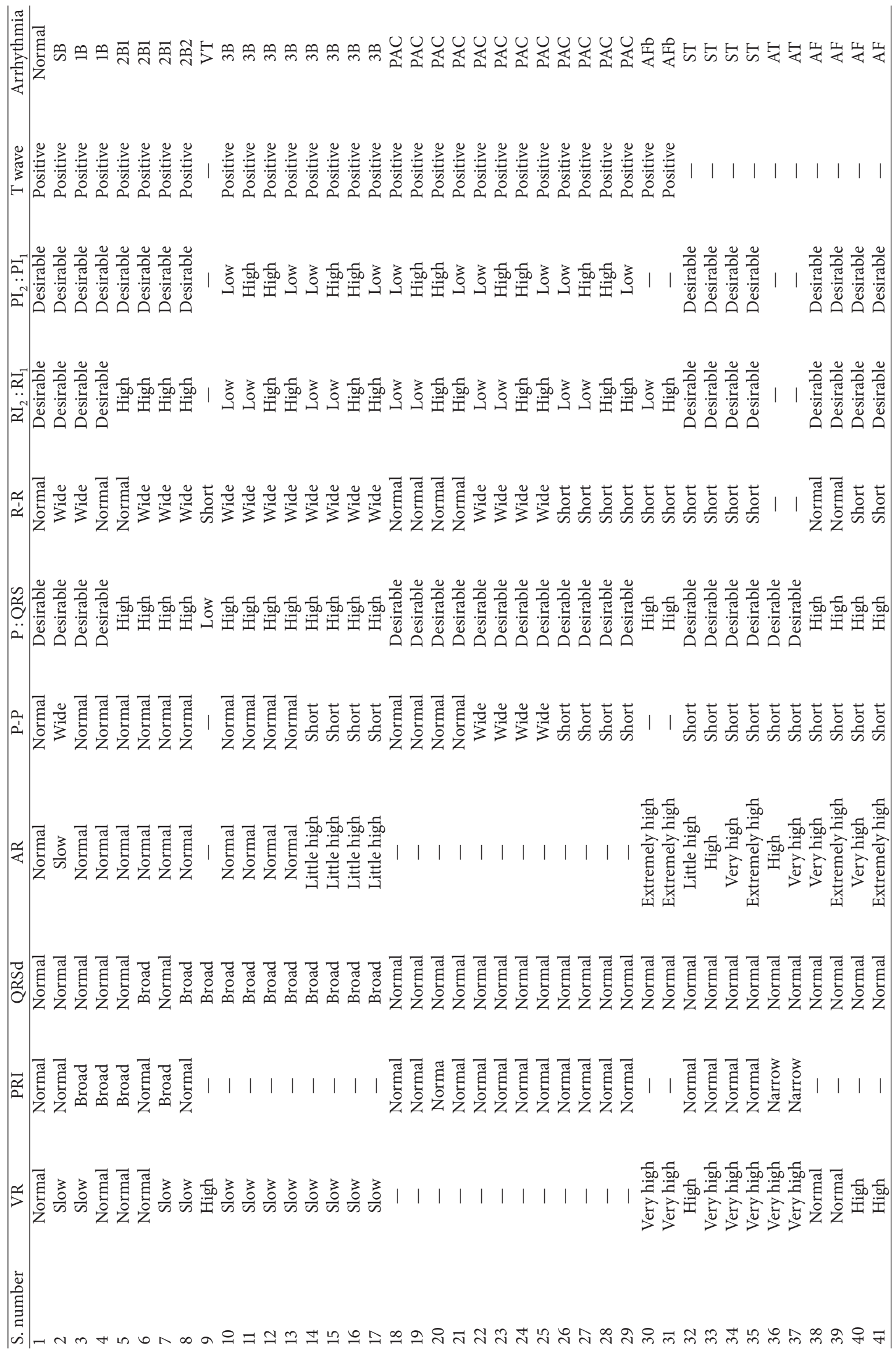




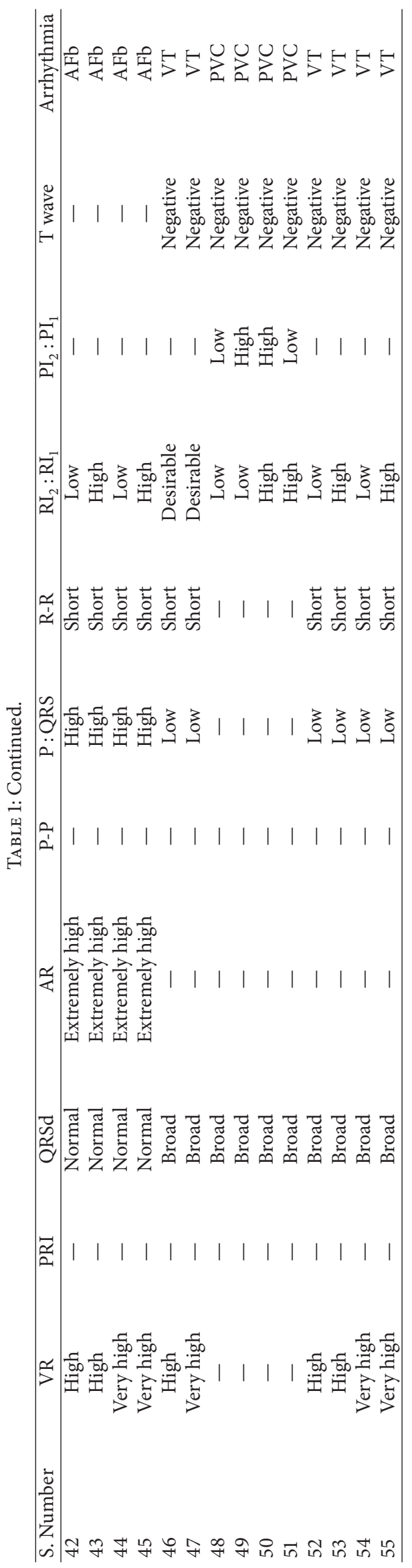




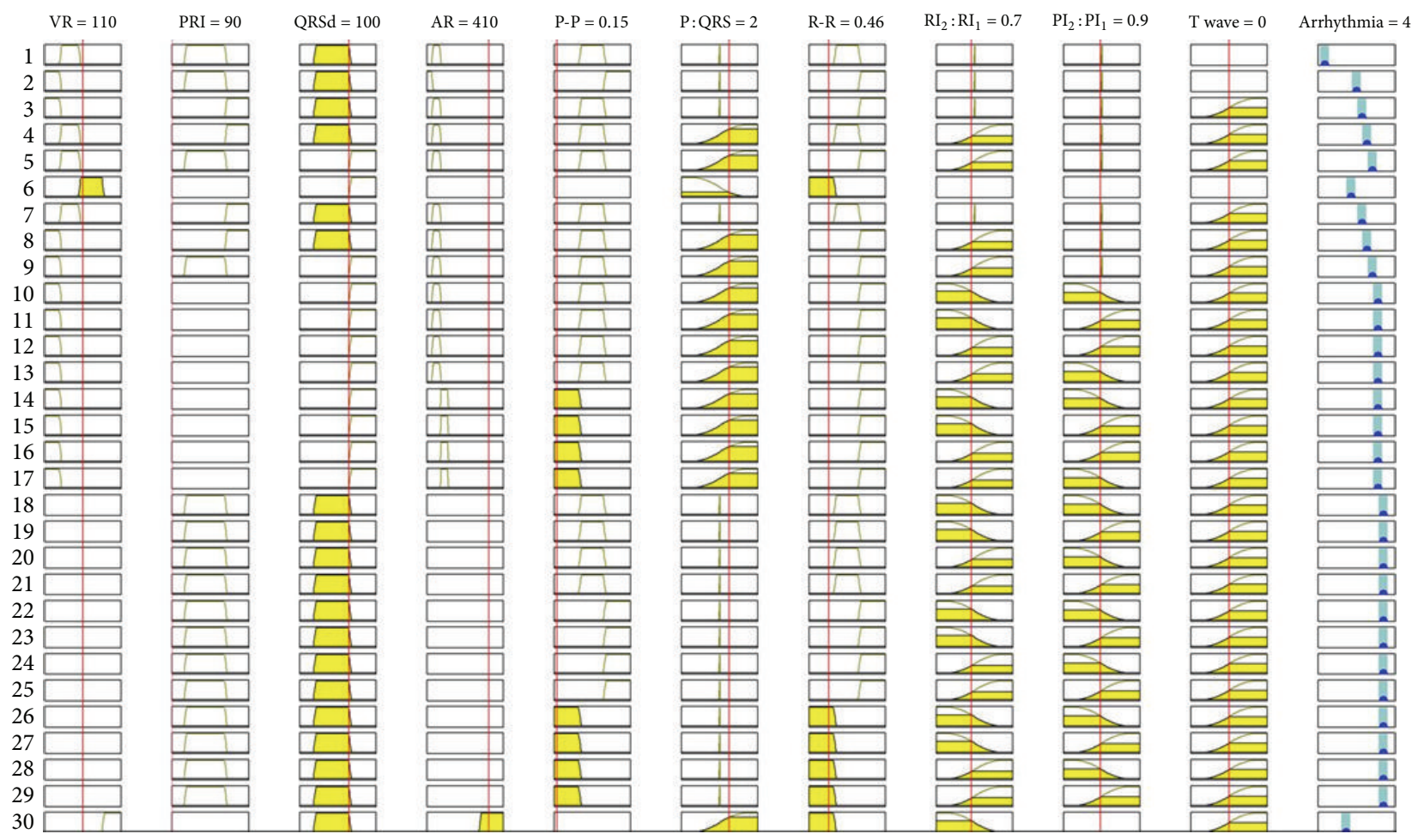

FIGURE 12: Designed information referral system.

Case 2. The ECG record of the concerned patient is manually calculated as follows.

$\mathrm{VR}=114 \mathrm{bpm}, \mathrm{PRI}=120 \mathrm{~ms}, \mathrm{QRSd}=296 \mathrm{~ms}, \mathrm{AR}=$ $20 \mathrm{bpm}, \mathrm{R}-\mathrm{R}$ interval $=0.52 \mathrm{sec}, \mathrm{P}-\mathrm{P}$ interval $=0.5 \mathrm{sec}, \mathrm{P}: \mathrm{QRS}$ $=0, \mathrm{RI}_{2}: \mathrm{RI}_{1}=1.2 \mathrm{PI}_{2}: \mathrm{PI}_{1}=1$ and $\mathrm{T}$ wave is negative.

Implementing these features, the Arrhythmia output is 8.59; that is, heart beat is Second AV Block Type 2 (2nd B2). Here, the observed diagnosis by medical expert is Ventricular Tachycardia (VT).

Values of Degree of Match of input parameters are computed and total Degree of Match of inputs $\mathrm{DM}_{T}$ is given below:

$$
\begin{aligned}
\mathrm{DM}_{T} & =\min \{1,1,1,1,1,1,0.778,0.564,0.5,0.778\} \\
& =0.5 .
\end{aligned}
$$

Degree of Match of output $\mathrm{DM}_{O}$ is -1 ; thus $D=\mid \mathrm{DM}_{T}-$ $\mathrm{DM}_{\mathrm{O}}|=| 0.5-(-1) \mid=1.5$ which does not lie between zero and one; therefore level of satisfaction is not good.

Case 3. The ECG record of the patient, as follows.

$\mathrm{VR}=40 \mathrm{bpm}, \mathrm{PRI}=120 \mathrm{~ms}, \mathrm{QRSd}=150 \mathrm{~ms}, \mathrm{AR}=91 \mathrm{bpm}$, $\mathrm{R}-\mathrm{R}$ interval $=1.5 \mathrm{sec}, \mathrm{P}-\mathrm{P}$ interval $=0.66 \mathrm{sec}, \mathrm{P}: \mathrm{QRS}=1.2$, $\mathrm{RI}_{2}: \mathrm{RI}_{1}=1.5, \mathrm{PI}_{2}: \mathrm{PI}_{1}=1$, and $\mathrm{T}$ wave is positive.

Implementing these features, the Arrhythmia output is 9.77; that is, heart beat is Third AV Block (3B). Here, the observed diagnosis by medical expert is the same, that is, Third AV Block (3B).
Values of Degree of Match of input parameters are computed and total Degree of Match of inputs $\mathrm{DM}_{T}$ is given below:

$$
\begin{aligned}
\mathrm{DM}_{T} & =\min \{1,1,1,1,1,1,0.564,0.653,0.5,0.778\} \\
& =0.5 .
\end{aligned}
$$

Degree of Match of output $\mathrm{DM}_{\mathrm{O}}$ is -1 ; thus $D=\mid \mathrm{DM}_{T}-$ $D M_{\mathrm{O}}|=| 0.5-(-1) \mid=1.5$ which does not meet level of satisfaction.

Case 4. The ECG record of the patient is as follows.

$\mathrm{VR}=104.89 \mathrm{bpm}, \mathrm{PRI}=164 \mathrm{~ms}, \mathrm{QRSd}=94 \mathrm{~ms}, \mathrm{AR}=$ $107.14 \mathrm{bpm}, \mathrm{R}-\mathrm{R}$ interval $=0.572 \mathrm{sec}, \mathrm{P}-\mathrm{P}$ interval $=0.56 \mathrm{sec}$, $\mathrm{P}: \mathrm{QRS}=1, \mathrm{RI}_{2}: \mathrm{RI}_{1}=1.2, \mathrm{PI}_{2}: \mathrm{PI}_{1}=1$, and $\mathrm{T}$ wave is positive.

Implementing these features, the Arrhythmia output is 9; that is, heart beat is Second AV Block Type. The evaluated diagnosis is verified by medical expert.

The satisfactory factor is $\left|\mathrm{DM}_{T}-\mathrm{DM}_{\mathrm{O}}\right|=|0.022-1|=$ 0.978 .

Case 5. The ECG record of the patient is as follows.

$\mathrm{VR}=132 \mathrm{bpm}, \mathrm{QRSd}=80 \mathrm{~ms}, \mathrm{R}-\mathrm{R}$ interval $=0.457 \mathrm{sec}$, $\mathrm{P}: \mathrm{QRS}=1.6, \mathrm{RI}_{2}: \mathrm{RI}_{1}=1.4$ and $\mathrm{T}$, wave is positive.

Implementing these features, the Arrhythmia output is 1; that is, heart beat is Sinus Tachycardia. The observed diagnosis by medical expert is Atrial Flutter.

The satisfactory factor is $\left|\mathrm{DM}_{T}-\mathrm{DM}_{\mathrm{O}}\right|=|0.63+1|=1.63$. 
Case 6. The ECG record of the patientis as follows.

$\mathrm{VR}=57.25 \mathrm{bpm}, \mathrm{PRI}=185 \mathrm{~ms}, \mathrm{QRSd}=73.2 \mathrm{~ms}, \mathrm{AR}=$ $57.25 \mathrm{bpm}, \mathrm{R}-\mathrm{R}$ interval $=1.048 \mathrm{sec}, \mathrm{P}-\mathrm{P}$ interval $=1.048 \mathrm{sec}$, $\mathrm{P}: \mathrm{QRS}=1, \mathrm{RI}_{2}: \mathrm{RI}_{1}=1, \mathrm{PI}_{2}: \mathrm{PI}_{1}=1$ and $\mathrm{T}$ wave is positive. Implementing these features, the Arrhythmia output is 0 ; that is, heart beat is Normal. The evaluated diagnosis is verified by medical expert.

The satisfactory factor is $\left|\mathrm{DM}_{T}-\mathrm{DM}_{\mathrm{O}}\right|=|0.55-1|=0.45$.

Case 7. The ECG record of the patient is as follows.

$\mathrm{VR}=61.37 \mathrm{bpm}, \mathrm{PRI}=168 \mathrm{~ms}, \mathrm{QRSd}=68 \mathrm{~ms}, \mathrm{AR}=$ $61.37 \mathrm{bpm}, \mathrm{R}-\mathrm{R}$ interval $=0.97 \mathrm{sec}, \mathrm{P}-\mathrm{P}$ interval $=0.97 \mathrm{sec}$, $\mathrm{P}: \mathrm{QRS}=1, \mathrm{RI}_{2}: \mathrm{RI}_{1}=1, \mathrm{PI}_{2}: \mathrm{PI}_{1}=1$, and $\mathrm{T}$ wave is positive. Implementing these features, the Arrhythmia output is 0 ; that is, heart beat is Normal. The evaluated diagnosis is verified by medical expert.

The satisfactory factor is $\left|\mathrm{DM}_{T}-\mathrm{DM}_{O}\right|=|0.5-1|=0.5$.

Case 8. The ECG record of the patient is as follows.

$\mathrm{VR}=91.3 \mathrm{bpm}, \mathrm{PRI}=152 \mathrm{~ms}, \mathrm{QRSd}=88 \mathrm{~ms}, \mathrm{AR}=$ $90.2 \mathrm{bpm}, \mathrm{R}-\mathrm{R}$ interval $=0.66 \mathrm{sec}, \mathrm{P}-\mathrm{P}$ interval $=0.67 \mathrm{sec}$, $\mathrm{P}: \mathrm{QRS}=1, \mathrm{RI}_{2}: \mathrm{RI}_{1}=1, \mathrm{PI}_{2}: \mathrm{PI}_{1}=1$, and $\mathrm{T}$ wave is positive.

Implementing these features, the Arrhythmia output is 0 ; that is, heart beat is Normal. The evaluated diagnosis is verified by medical expert.

The satisfactory factor is $\left|\mathrm{DM}_{T}-\mathrm{DM}_{O}\right|=|0.5-1|=0.5$.

Case 9. The ECG record of the patient is as follows.

$\mathrm{VR}=41.5 \mathrm{bpm}, \mathrm{PRI}=150 \mathrm{~ms}, \mathrm{QRSd}=98 \mathrm{~ms}, \mathrm{AR}=$ $40 \mathrm{bpm}, \mathrm{R}-\mathrm{R}$ interval $=1.45 \mathrm{sec}, \mathrm{P}-\mathrm{P}$ interval $=1.49 \mathrm{sec}$, $\mathrm{P}: \mathrm{QRS}=1, \mathrm{RI}_{2}: \mathrm{RI}_{1}=1, \mathrm{PI}_{2}: \mathrm{PI}_{1}=1$, and $\mathrm{T}$ wave is positive.

Implementing these features, the Arrhythmia output is 6; that is, heart beat is Sinus Bradycardia. The evaluated diagnosis is verified by medical expert.

The satisfactory factor is $\left|\mathrm{DM}_{T}-\mathrm{DM}_{\mathrm{O}}\right|=|0.6-1|=0.4$.

Case 10. The ECG record of the patient is as follows.

$\mathrm{VR}=61.3 \mathrm{bpm}, \mathrm{PRI}=134 \mathrm{~ms}, \mathrm{QRSd}=65 \mathrm{~ms}, \mathrm{AR}=$ $59 \mathrm{bpm}, \mathrm{R}-\mathrm{R}$ interval $=0.98 \mathrm{sec}, \mathrm{P}-\mathrm{P}$ interval $=0.99 \mathrm{sec}$, $\mathrm{P}: \mathrm{QRS}=1, \mathrm{RI}_{2}: \mathrm{RI}_{1}=1, \mathrm{PI}_{2}: \mathrm{PI}_{1}=1$, and $\mathrm{T}$ wave is positive.

Implementing these features, the Arrhythmia output is 6; that is, heart beat is Normal. The evaluated diagnosis is verified by medical expert.

The satisfactory factor is $\left|\mathrm{DM}_{T}-\mathrm{DM}_{O}\right|=|0.5-1|=0.5$.

\section{Conclusion}

The proposed system is capable enough to categorize an ECG waveform into one of the thirteen types of Arrhythmia. The results obtained from the soft system concur with the results provided by experts in 91 out of 105 cases. As available in literature we have observed that classifiers introduced so far cater different types of Arrhythmia, mostly based on databases from western countries. This work is significant as it caters to the most commonly occurring Arrhythmias and provides an easy and reliable tool to apply in real time systems and automation projects, for use in ICU and patient monitoring systems. It can also be used in day-today diagnosis of Arrhythmia by implementing the technique in stand-alone systems. Hence the relevance of this work, which is intended to be incorporated into primary care health facilities catering to a wide patient base, helping timely detection and lessening mortality rates.

\section{Conflict of Interests}

All authors, Pankaj Srivastava, Neeraja Sharma and C. S. Aparna disclose that there is no conflict of interests. There are also neither financial nor personal relationships with other people or organizations mentioned in this work that could cause any inappropriate influence.

\section{Acknowledgments}

The authors sincerely thank the cardiologists Dr. Geeta Shukla, MD, and Dr. Omar Hasan, DM (Nazarth Hospital, Allahabad, India), for their valuable suggestions and providing data in the preparation of the present paper.

\section{References}

[1] K. Lochan, Bhaisajya Ratnavali of Govinda Dasji Bhisagratna, Chaukhambh, New Delhi, India, 2008.

[2] B. Lüderitz, "Historical perspectives of cardiac electrophysiology," Hellenic Journal of Cardiology, vol. 50, no. 1, pp. 3-16, 2009.

[3] H. J. J. Wellens, "Cardiac arrhythmias: the quest for a curea historical perspective," Journal of the American College of Cardiology, vol. 44, no. 6, pp. 1155-1163, 2004.

[4] S. Z. Mahmoodabadi, A. Ahmadian, M. Abolhasani, P. Babyn, and J. Alirezaie, "A fast expert system for electrocardiogram arrhythmia detection," Expert Systems, vol. 27, no. 3, pp. 180200, 2010.

[5] R. E. Bellman and L. A. Zadeh, "Decision making in a fuzzy environment," Management Science, vol. 17, no. 4, pp. B141-B164, 1970.

[6] L. A. Zadeh, "Outline of a new approach to the analysis of complex systems and decision processes," IEEE Transactions on Systems, Man and Cybernetics, vol. 3, no. 1, pp. 28-44, 1973.

[7] W. Zong and D. Jiang, "Automated ECG rhythm analysis using fuzzy reasoning," Computers in Cardiology, vol. 25, pp. 69-72, 1998.

[8] P. de Chazal, M. O’Dwyer, and R. B. Reilly, "Automatic classification of heartbeats using ECG morphology and heartbeat interval features," IEEE Transactions on Biomedical Engineering, vol. 51, no. 7, pp. 1196-1206, 2004.

[9] Y.-C. Yeh, W.-J. Wang, and C. W. Chiou, "Heartbeat case determination using fuzzy logic method on ECG signals," International Journal of Fuzzy Systems, vol. 11, no. 4, pp. 250261, 2009.

[10] I. Sadiq and S. A. Khan, "Heart beat classification of ECGs using morphology and beat intervals," in Proceedings of the 5th International Conference on Bioinformatics and Biomedical Engineering (iCBBE '11), May 2011.

[11] P. Srivastava and A. Srivastava, "A note on soft computing approach for cardiac analysis," Journal of Basic and Applied Scientific Research, vol. 2, no. 1, pp. 376-385, 2012.

[12] P. Srivastava and A. Srivastava, "Spectrum of soft computing risk assessment scheme for hypertension," International Journal of Computer Applications, vol. 44, no. 17, pp. 23-30, 2012. 
[13] P. Srivastava, A. Srivastava, and R. Sirohi, "Soft computing tools and classification criterion for Hepatitis B," International Journal of Research and Reviews in Soft \& Intelligent Computing, vol. 2, no. 2, pp. 147-153, 2012.

[14] P. Srivastava and N. Sharma, Soft Computing Criterion For ECG Beats Classification and Cardiac Analysis.

[15] P. Srivastava, N. Sharma, and R. Singh, "Soft computing diagnostic system for diabetes," International Journal of Computer Applications, vol. 47, no. 18, pp. 22-27, 2012.

[16] P. Srivastava and N. Sharma, "A spectrum of soft computing model for medical diagnosis," Applied Mathematics \& Information Sciences, vol. 8, no. 3, pp. 1225-1230, 2014.

[17] S. Cho, O. K. Ersoy, and M. Lehto, "An algorithm to compute the degree of match in fuzzy systems," Fuzzy Sets and Systems, vol. 49, no. 3, pp. 285-299, 1992. 


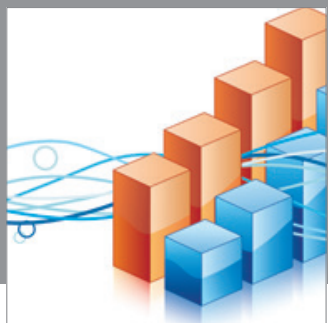

Advances in

Operations Research

mansans

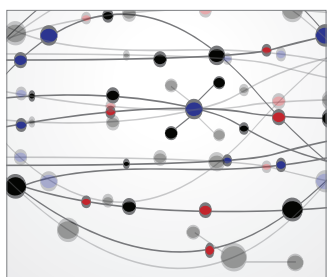

The Scientific World Journal
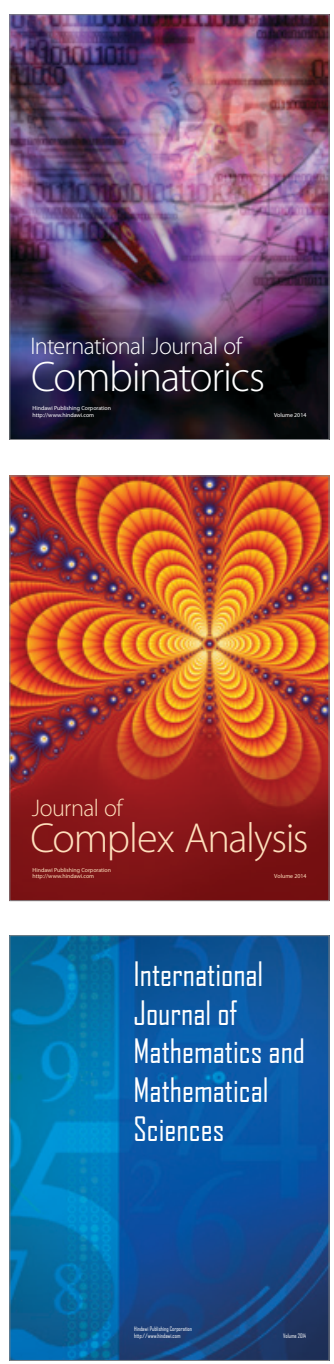
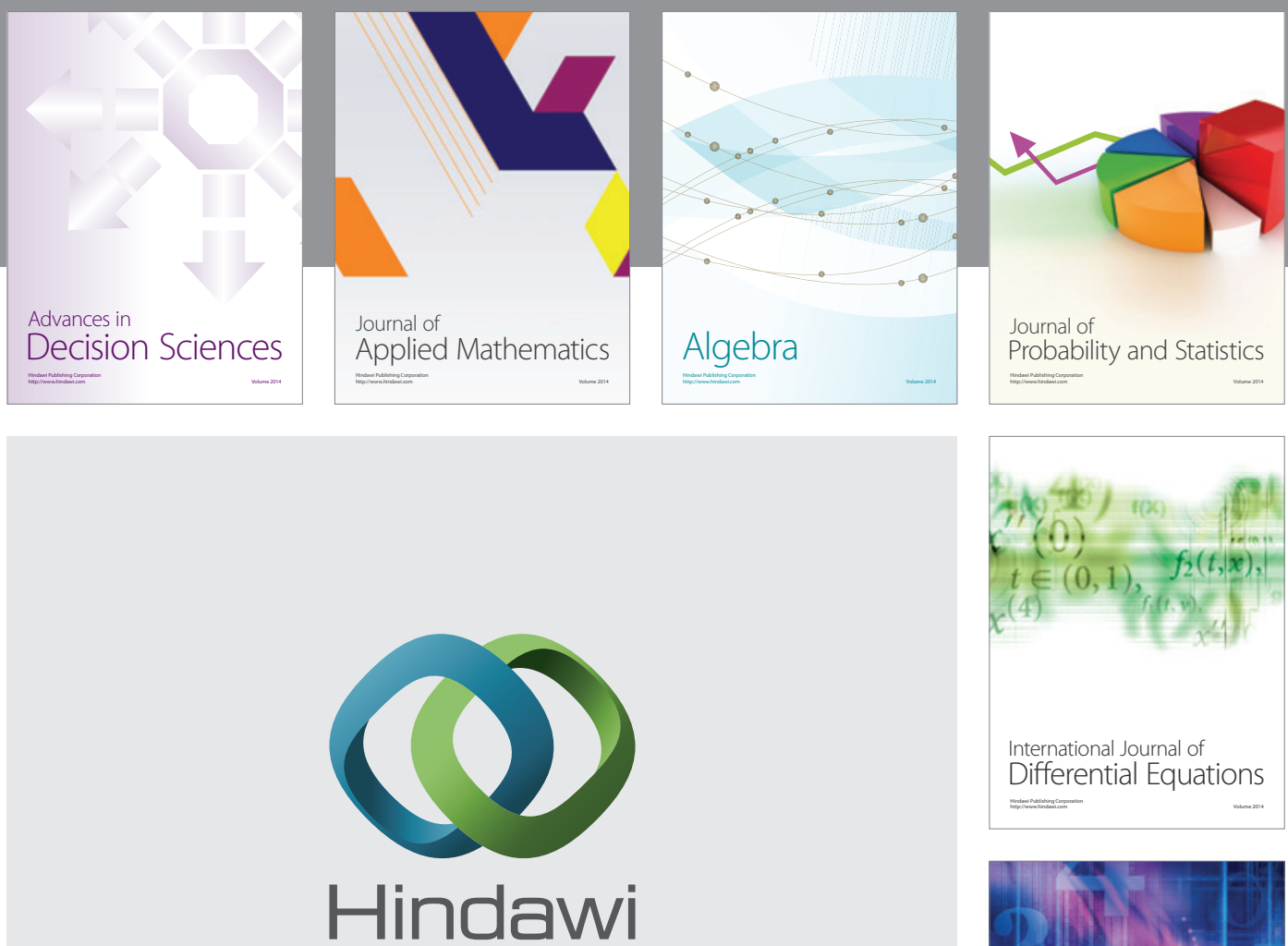

Submit your manuscripts at http://www.hindawi.com
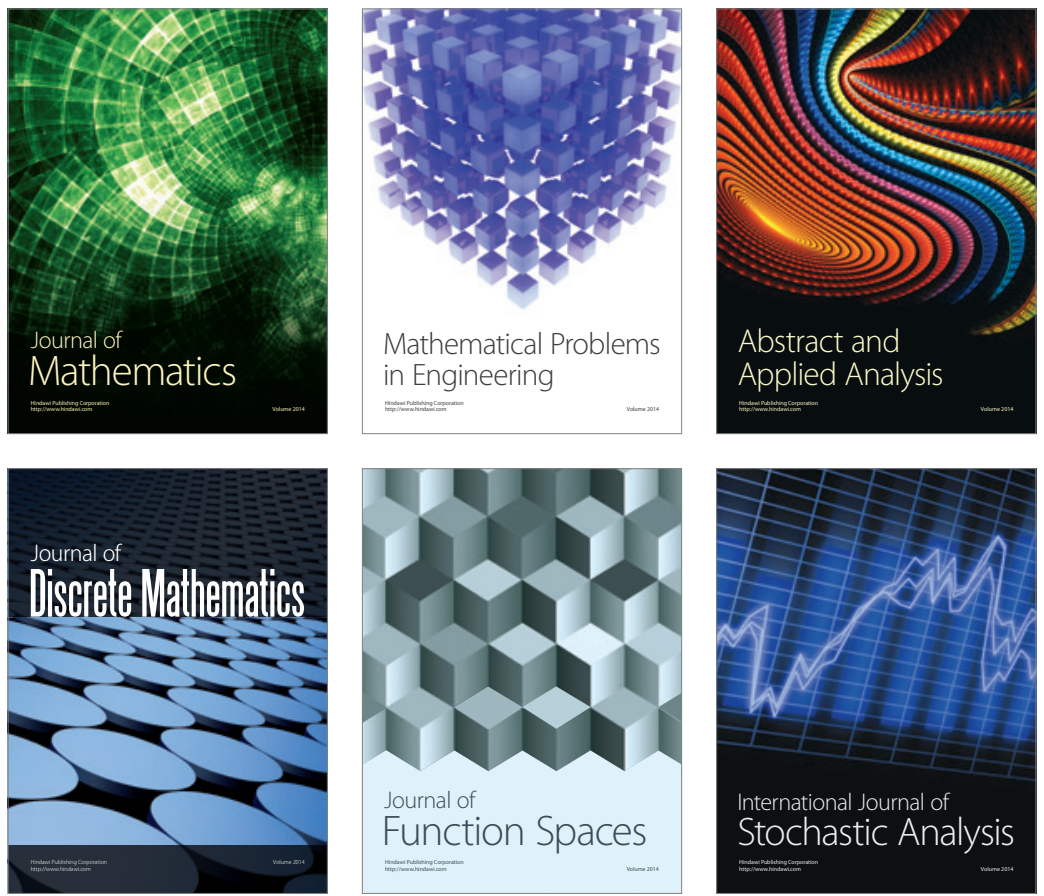

Journal of

Function Spaces

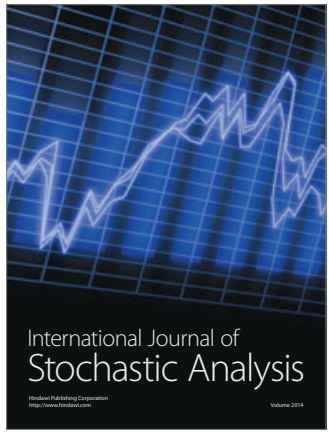

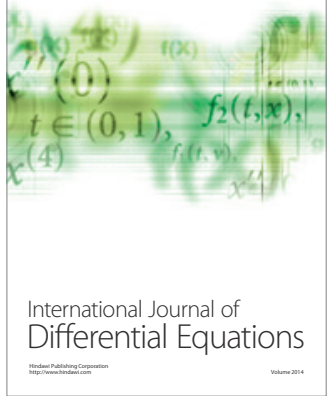
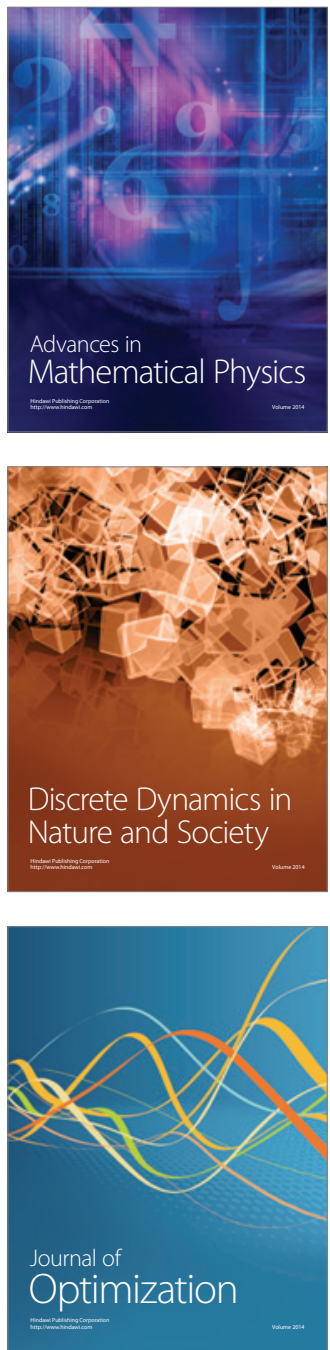